\title{
Valve-related factors and incidence of prosthetic valve endocarditis
}

\author{
Branislav Bezak, Panagiotis Artemiou, Michal Hulman \\ National Institute of Cardiovascular Diseases, Clinic of Cardiac Surgery, Medical Faculty of the Comenius \\ University, Bratislava, Slovak Republic
}

Kardiochir Torakochir Pol 2020; 17 (4): 178-182

\begin{abstract}
Aim: The aim of the study was to present our experience and evaluate the valve-related factors and the incidence of prosthetic valve endocarditis.

Material and methods: This is a retrospective study. Between 2010 and 2018, 36 patients were re-operated on due to prosthetic valve endocarditis The valve-related factors (type, size and position of the prosthetic valve) were analysed.

Results: Thirty-six patients had prosthetic valve endocarditis. The overall hospital mortality was $16.67 \%$. Early vs. late onset prosthetic valve endocarditis mortality was $23.08 \%$ vs. $13.04 \%$ respectively. The type, size or position of the prosthesis was not associated with prosthetic valve endocarditis. There was a statistically significant difference between occurrence of prosthetic infection between mitral repair and replacement both in mechanical and biological valve groups. The most common infective agent in the early onset group was Staphylococcus aureus, whereas in the late onset group it was Enterococcus faecalis. Out of 13 patients with early prosthetic valve endocarditis, 11 had infection in the perioperative period around primary operation. Conclusions: Based on our experience, prosthetic valve endocarditis has a high mortality. Early onset prosthetic valve endocarditis is less common but has higher mortality compared to the late onset. Mitral valve repair was less prone to develop prosthetic valve endocarditis, and valve-related factors (type and size of the valve, valve position) did not have any influence on the incidence of prosthetic valve endocarditis.
\end{abstract}

Key words: prosthetic valve endocarditis, valve-related factors.

\section{Introduction}

Prosthetic valve endocarditis (PVE) is a life-threatening complication which accounts for $10-30 \%$ of all cases of infective endocarditis [1, 2]. PVE affects $1-6 \%$ of patients with prosthetic valve implants [3].

The diagnosis is based on clinical findings, laboratory tests, echocardiography and operative findings [4]. Patients with PVE undergoing valve reoperations show lower 30-day mortality and greater survival at follow-up compared with medical therapy [5]. Nevertheless, the in-hospital mortality is very high, ranging from $20 \%$ to $40 \%$ [3], with some sources reporting mortality as high as $80 \%$ [6].

Prosthetic valve endocarditis is usually defined as early or late based on the time period between the primary operation and onset of PVE. The most commonly reported threshold is 1 year. This definition is however arbitrary. It is more important to determine whether IE was acquired perioperatively and which microorganism is involved [3].

Some risk factors appear more frequently, such as a recent episode of infectious endocarditis, postoperative blood- stream infection and surgical wound infection [7]. However, others are not well defined in the literature and results between different series vary. For example, choice of prosthesis (mechanical vs. biological), position (mitral vs. aortic), concomitant coronary surgery, cardiopulmonary bypass time and many others show controversial results $[2,3,8,9]$.

\section{Aim}

The aim of this study was to present our experience and evaluate the valve-related factors and the incidence of PVE.

\section{Material and methods \\ Patient selection}

This retrospective study was conducted at the Clinic of Cardiac Surgery at the National Institute of Cardiovascular Diseases in Bratislava, and included patients who underwent cardiac surgery for prosthetic valve endocarditis at our clinic within the years 2010-2018. During that time $36(0.86 \%)$ patients were operated on due to PVE from

Address for correspondence: Panagiotis Artemiou PhD, National Institute of Cardiovascular Diseases, Clinic of Cardiac Surgery, Medical Faculty of the Comenius University, Bratislava, Slovak Republic, phone: +42 1917665774, e-mail: panayiotisartemiou@yahoo.com Received: 23.06.2020, accepted: 24.10.2020. 
a total of 4165 valve procedures. Indications for surgery included severe hemodynamic impairment due to acute paravalvular insufficiency, prosthetic valve dysfunction due to vegetations, recurrent major embolism or large vegetations and abscess or perivalvular involvement.

Early PVE was defined as endocarditis of the prosthetic valve within a year after the primary operation. There were 13 patients with early and 23 with late onset PVE.

The patients' characteristics that were analysed were: gender, age, body mass index (BMI) and EuroSCORE II. Six $(16.67 \%)$ patients were primarily operated for bacterial endocarditis and 23 (64\%) patients had an infection during the perioperative period of the primary procedure. The following valve-related risk factors were analysed: type, size and position of the prosthetic valve. Patients who were treated conservatively, undiagnosed, contraindicated for operation or operated in different hospital were not included in the study. Informed consent and institutional review board permission were obtained to present these results.

\section{Statistical analysis}

After processing individual data we used Fisher's exact test to determine statistical significance. We preferred Fisher's test over the $\chi^{2}$ test because some of the analysed groups of patients were relatively small and would cause the $\chi^{2}$ test to be invalid. The probability randomness threshold was set for 0.01, meaning there is substantial evidence against the null hypothesis. Numerical variables were presented as mean with minimal, maximal and median values, and categorised variables were summarised by percentages. For the statistical analysis we used statistical analysis tools available at http://www.socscistatistics.com.

\section{Results}

In the period between 2010 and 2018 in our institution, 4165, aortic or mitral valvular procedures were performed and $36(0.86 \%)$ patients patients had a reoperation due to PVE. There were 13 (36.1\%) patients with early and 23 (63.9\%) with late onset PVE .

The study population consisted of a total of 25 (69.44\%) men and 11 (30.56\%) women. The median age was 59.5 (34-81) years, BMI $28.5(22.2-37.04) \mathrm{kg} / \mathrm{m}^{2}$ and EuroSCORE II $11 \%$ (4-22.56). Twenty (55.56\%) of these patients had infection in the perioperative period of the primary operation and $6(16.67 \%)$ patients were primarily operated for bacterial endocarditis. Eleven patients had a bloodstream infection, 3 patients sternal wound infection, 3 patients postoperative pneumonia, 2 patients urinary tract infection, and 1 patient sternal wound infection and postoperative pneumonia. From the 6 patients who were primarily operated on for bacterial endocarditis, 2 had a positive postoperative prosthetic valve culture and 2 had a positive perioperative blood culture.

\section{Biological vs. mechanical prosthesis}

There was no statistically significant difference in the incidence of PVE in patients after aortic valve replacement, mitral valve replacement or Bentall procedure. In the aor- tic valve position the incidence for mechanical valves was $1.31 \%$ and $0.81 \%$ for biological valves $(p=0.2198)$, in the mitral valve position $1.35 \%$ for mechanical valve and $3.38 \%$ for biological valve $(p=0.4475)$, in the Bentall group $9.09 \%$ for mechanical composite graft and $0 \%$ for biological composite graft $(p=0.4475)$ (Table I).

\section{Valve size}

There was no statistically significant difference in the incidence of PVE between different valves sizes in aortic position both in the mechanical and biological valve group ( $p=0.5879$ and $p=0.9230$ respectively) (Tables I, II).

\section{Mitral repair vs. replacement}

There was a statistically significant difference between occurrence of prosthetic infection between mitral repair and replacement both in mechanical (repair 0.095\%, replacement $1.35 \%, p=0.0416)$ and biological valve groups (repair $0.095 \%$, replacement 3.38\%, $p=0.0001$ ).

\section{Prosthesis position}

There was no statistically significant difference between aortic and mitral position of mechanical valves $(1.31 \%$ and $1.35 \%$ respectively, $p=1$ ). In the biological group there was a statistically significant lower rate of PVE in aortic position compared to mitral ( $0.81 \%$ vs. $3.38 \%, p=0.0128)$ (Table III).

\section{Microbial agents}

The most common microbial agent was Enterococcus faecalis (25\%), followed by coagulase-negative staphylococci $(22.22 \%)$ and Staphylococcus aureus (22.22\%). Viridans streptococci were present in $5.56 \%$. There was one

Table I. Results and incidence of prosthetic valve endocarditis overall

\begin{tabular}{lccc} 
Procedure & Endocarditis & Total & Incidence (\%) \\
AVR mechanical & 12 & 916 & 1.31004367 \\
\hline AVR biological & 15 & 1859 & 0.80688542 \\
\hline MVR mechanical & 2 & 148 & 1.35135135 \\
\hline MVR biological & 5 & 148 & 3.37837838 \\
\hline MVP & 1 & 1053 & 0.09496676 \\
\hline Mechanical Bentall & 2 & 22 & 9.09090909 \\
\hline Biological Bentall & 0 & 19 & 0 \\
\hline Overall & 36 & 4165 & 0.86 \\
\hline
\end{tabular}

AVR - aortic valve replacement, MVR - mitral valve replacement, MVP - mitral valve repair.

Table II. Results and incidence of prosthetic valve endocarditis dependant on biological valve size $(p=0.9230)$

\begin{tabular}{lccc} 
Prosthesis size & Endocarditis & Total & Incidence (\%) \\
19 & 1 & 151 & 0.66225166 \\
\hline 21 & 3 & 477 & 0.62893082 \\
\hline 23 & 7 & 622 & 1.12540193 \\
\hline 25 & 3 & 340 & 0.88235294 \\
\hline 27 & 1 & 140 & 0.71428571 \\
\hline
\end{tabular}


Table III. Results and incidence of prosthetic valve endocarditis dependant on mechanical valve size $(p=0.5879)$

\begin{tabular}{lccc} 
Prosthesis size & Endocarditis & Total & Incidence (\%) \\
19 & 2 & 67 & 2.98507463 \\
\hline 21 & 1 & 153 & 0.65359477 \\
\hline 23 & 4 & 252 & 1.58730159 \\
\hline 25 & 1 & 157 & 0.63694268 \\
\hline 27 & 1 & 94 & 1.06382979 \\
\hline
\end{tabular}

case caused by Pseudomonas aeruginosa (2.78\%), one case by Morganella morganii (2.78\%) and one by oxacillinresistant Staphylococcus lentis (2.78\%). In 4 (11.11\%) cases the haemocultures and peroperative swabs taken from the prosthesis were negative and in 4 (11.11\%) cases the pathogen was not stated (information was acquired retrospectively from patient documentation).

In the early onset group the most common infective agent was Staphylococcus aureus (30.77\%), followed by Enterococcus faecalis (23.08\%) and coagulase-negative staphylococci (15.38\%). In the late onset group the most common infective agent was Enterococcus faecalis (26.09\%) and coagulase-negative staphylococci (26.09\%), followed by Staphylococcus aureus (17.39\%).

Out of 13 patients with early PVE 11 (84.62\%) had an infection during the perioperative period of the primary operation (Table IV).

\section{Mortality}

The overall hospital mortality was $16.67 \%$ (6 patients). In the group with early onset of PVE the mortality was however almost double compared to late onset (23.08\% vs. $13.04 \%)$.

\section{Discussion}

In our study the incidence of PVE was $0.86 \%$, where $36.1 \%$ of the patients had early onset and $63.9 \%$ had late onset PVE. The incidence of PVE in the aortic position (29 patients, $80.56 \%$ ) was higher than in the mitral position (7 patients, 19.44\%). Our results show that the incidence of PVE is similar to that reported by other studies [1, 2, 6-9].

In our study, the presence of infection in the postoperative period of the primary operation was associated with an increased incidence of PVE, where 11 patients with early PVE had such infection. The most closely related infection, as in our study, was primary bloodstream infections, which is considered a causal factor for PVE, together with the direct contamination of the prosthesis that may occur during the surgical procedure [8, 10-13]. Other authors, like us have found the presence of surgical wound infection and fever in the postoperative period as a risk factor $[9,14,15]$.

In our study, we found no statistically significant difference in the incidence of PVE between the use of mechanical or biologic prosthetic valves. Flynn et al. [16] found, in a meta-analysis of surgical outcomes comparing mechanical valve replacement and bioprosthetic valve replacement in infective endocarditis, no significant difference in risk of recurrent endocarditis between mechanical and biological valves. They recommend that the decision of which type of valve prosthesis should be implanted be based on patient age, co-morbidities and preferences. Moreover, the European Society of Cardiology guidelines for the management of infective endocarditis state that PVE affects biological and mechanical valves equally [3]. The current AATS guidelines [17] for surgical treatment of endocarditis state that for patients requiring valve replacement, there is little evidence that risk of recurrent infection is different between mechanical and tissue prostheses. They recommend that the choice of replacement valves should be based on the usual criteria. However, in recent registry studies from Sweden and Denmark when comparing incidence of endocarditis following valve replacement of non-infected pathologies, bioprostheses were associated with higher risk of endocarditis than mechanical prostheses [2, 18].

An alternative, especially useful in the aortic position in infective endocarditis with significant disruption of the annulus, is the homograft. Several works appear to indicate that homografts may be more resistant to infection than either biological or mechanical prostheses $[19,20]$. However, others have shown no difference in the rates of re-infection [21].

Concerning the valve size, in our study, there was no statistically significant difference in the incidence of PVE between different valve sizes in the aortic position both in the mechanical and biological valve group. In the published literature, there are no data on the association between

Table IV. Infective agents

\begin{tabular}{|c|c|c|c|c|c|c|}
\hline \multirow[t]{2}{*}{ Infective agent } & \multicolumn{2}{|c|}{ Total } & \multicolumn{2}{|c|}{ Early } & \multicolumn{2}{|c|}{ Late } \\
\hline & $N$ & $\%$ & $N$ & $\%$ & $N$ & $\%$ \\
\hline Negative swabs & 4 & 11.11 & 0 & 0.00 & 4 & 17.39 \\
\hline Not stated & 4 & 11.11 & 1 & 7.69 & 3 & 13.04 \\
\hline Staphylococcus aureus & 8 & 22.22 & 4 & 30.77 & 4 & 17.39 \\
\hline Enterococcus faecalis & 9 & 25.00 & 3 & 23.08 & 6 & 26.09 \\
\hline Coagulase-negative staphylococci & 8 & 22.22 & 2 & 15.38 & 6 & 26.10 \\
\hline Streptococcus viridans & 2 & 5.56 & 0 & 0.00 & 2 & 8.69 \\
\hline Staphylococcus lentis oxacillin resistant & 1 & 2.78 & 1 & 7.69 & 0 & 0.00 \\
\hline Pseudomonas aeruginosa & 1 & 2.78 & 0 & 0.00 & 1 & 4.35 \\
\hline
\end{tabular}


the valve size of the prosthetic valve and the incidence of PVE.

A purported advantage of mitral valve repair over replacement is greater freedom from valve-related morbidity, including endocarditis. In our study a statistically significant difference was found between occurrence of prosthetic infection between mitral repair and replacement both in the mechanical and the biological valve group. This finding is similar to data published by other authors, who reported ten-year freedom from endocarditis after mitral valve repair $95 \%$ to $99 \%$ [22-24].

In our study, we identified a higher incidence of PVE in biological valves in the mitral position than in the aortic position. Concerning the mechanical valves there was no difference. The low number of patients with PVE after mitral valve replacement may contribute to this finding. In contrast, data from other authors showed no difference in the incidence of PVE according the valve position, or reported that the aortic position is more prone to infection $[5-8,25]$.

The most common microbial agent reported in our study was Enterococcus faecalis, followed by coagulase-negative staphylococci and Staphylococcus aureus. In the early onset group the most common infective agent was Staphylococcus aureus, whereas in the late group the most common agent was Enterococcus faecalis. Moreover, infection with S. aureus is the leading cause of PVE in most epidemiologic studies and represents a high-risk subgroup in this population $[25,26]$. On the other hand, other authors reported S. epidermidis as the most frequent causative microorganism $[7,27]$.

Overall mortality in our study was $16.67 \%$, which is comparable with data from other studies. A meta-analysis by Mihos et al. [5] and a multicentre analysis from Germany [25] reported 30 -day mortality of $25 \%$ and $19.6 \%$ respectively. The mortality in patients in our study with early PVE was almost twice as high (13.04\% vs. $23.08 \%$ ) compared with late PVE. Higher mortality in early than in late PVE was also reported by Tugtekin et al. [6].

There are some limitations in our study that should be considered when interpreting the results. It is a single centre retrospective study, with a small cohort of patients. The small number of patients in the cohort may influence the results.

\section{Conclusions}

Based on our experience, PVE has a high mortality. Early onset PVE is less common but has higher mortality compared to the late onset. Mitral valve repair was less prone to develop PVE, and valve-related factors (type and size of the valve, valve position) did not have any influence on the incidence of PVE.

\section{Disclosure}

The authors report no conflict of interest.

\section{References}

1. Habib G, Franck T, Avierinos JF. Prosthetic valve endocarditis: current ap proach and therapeutic options. Prog Cardiovasc Dis 2008; 50: 274-281.

2. Glaser N, Jackson V, Holzman MJ, Franco-Cereda A, Sartipy U. Prosthetic valve endocarditis after surgical aortic valve replacement. Circulation 2017; 136: 329-331.

3. Habib G, Lancelloti P, Antunes MJ, Bongiorni MG, Casalta JP, Del Zotti F, Dulgheru R, El Khoury G, Erba PA, lung B, Miro JM, Mulder BJ, Plonska-Gosciniak E, Price S, Roos-Hesselink J, Snygg-Martin U, Thuny F, Mas PT, Vilacosta I, Zamorano JL, ESC Scientific Document Group. 2015 ESC guidelines for the management of infective endocarditis: the task force for the management of infective endocarditis of the European Society of Cardiology (ESC) endorsed by: European Association for Cardio-Thoracic Surgery (EACTS), the European Association of Nuclear Medicine (EANM). Eur Heart J 2015; 36: 3075-3128.

4. Nagpal A, Muhammad S, Steckelberg J. Prosthetic valve endocarditis: state of the heart. Clin Invest 2012; 2: 803-817.

5. Mihos CG, Capoulade R, Yucel E, Picard MH, Santana O. Surgical versus medical therapy for prosthetic valve endocarditis: a meta-analysis of 32 studies. Ann Thorac Surg 2017; 103: 991-1004.

6. Tugtekin S, Matschke K, Daubner D, Kappert U, Schueler S, Wilbring M, Knaut M, Alexiou K. Prosthetic valve endocarditis: importance of surgical treatment. Thorac Cardiov Surg 2007; 55: 94-98.

7. Garrido RQ, Pessanha B, Andrade N, Correia MG, Weksler C, Golebiovski W, Barbosa GF, Garrido MM, Martins IS, Lamas CC. Risk factors for early onset prosthetic valve endocarditis. J Hosp Infect 2018; 100: 437-443.

8. Arvay A, Lengyel M. Incidence and risk factors of prosthetic valve endocarditis. Eur J Cardiothorac Surg 1998: 2: 340-346.

9. Farinas MC, Perez-Vazquez A, Farinas-Alvarez C, García-Palomo JD, Bernal JM, Revuelta JM, González-Macías J. Risk factors of prosthetic valve endocarditis: a case-control study. Ann Thorac Surg 2006; 81: 1284-1290.

10. Fang G, Keys TF, Gentry LO, Harris AA, Rivera N, Getz K, Fuchs PC, Gustafson M, Wong ES, Goetz A, Wagener MM, Yu VL. Prosthetic valve endocarditis resulting from nosocomial bacteremia. A prospective, multicenter study. Ann Intern Med 1993; 119: 560-567.

11. Benito N, Pericas JM, Gurgui M, Mestres CA, Marco F, Moreno A, Horcajada JP, Miró JM. Health care-associated infective endocarditis: a growing entity that can be prevented. Curr Infect Dis Rep 2014; 16: 439.

12. Que YA, Moreillon P. Infective endocarditis Nat Rev Cardiol 2011; 8: 322-336.

13. Giamarellou H. Nosocomial cardiac infections. J Hosp Infect 2002; 50: 91-105.

14. Gover FL, Cohen DJ, Oprian C, Henderson WG, Sethi G, Hammermeister KE. Determinants of the occurrence of and survival from prosthetic valve en docarditis. Experience of the veteran Affairs Cooperative Study on Valvular Heart Disease. J Thorac Cardiovasc Surg 1994; 108: 207-214.

15. Saget A, Sanjong R, Muhammad AG. Risk factors for prosthetic valve endocarditis - a case control study. Indian J Thorac Cardiovasc Surg 2009; 25: 102-106.

16. Flynn CD, Curran NP, Chan S, Zegri-Reiriz I, Tauron M, Tian DH, Pettersson GB, Coselli JS, Misfeld M, Antunes MJ, Mestres CA, Quintana E. Systematic review and meta-analysis of surgical outcomes comparing mechanical valve replacement and bioprosthetic valve replacement in infective endocarditis. Ann Cardiothrac Surg 2019; 8: 587-599.

17. Petterson GB, Coselli JS, Hussain ST. The American Association for Thoracic Surgery (AATS) consensus guidelines: surgical treatment of infective endocarditis:Executive summary. J Thorac Cardiovasc Surg 2017; 153: 1241 1258.e29.

18. Ostergaard L, Valeur N, Ihlemann N, Smerup MH, Bundgaard H, Gislason G, Torp-Pedersen C, Bruun NE, Køber L, Fosbøl EL. Incidence and factors associated with infective endocarditis in patients undergoing left-sided heart valve replacement. Eur Heart J 2018; 39: 2668-2675.

19. Musci M, Weng Y, Hubler M, Amiri A, Pasic M, Kosky S, Stein J, Siniawski H, Hetzer R. Homograft aortic root replacement in native or prosthetic active infective endocarditis: twenty-year single center experience. J Thorac Cardiovasc Surg 2010; 139: 665-673.

20. Solari S, Mastrobuoni S, De Kerchove L, Navarra E, Astarci P, Noirhomme $P$, Poncelet A, Jashari R, Rubay J, El Khoury G. Over 20 years experience with aortic homograft in aortic valve replacement during active infective endocarditis. Eur J Cardiothorac Surg 2016; 50: 1158-1164.

21. Kim JB, Ejiofor JI, Yammine M, Camuso JM, Walsh CW, Ando M, Melnitchouk SI, Rawn JD, Leacche M, MacGillivray TE, Cohn LH, Byrne JG, Sundt TM. Are homografts superior to conventional prosthetic valves in the 
setting of infective endocarditis involving the aortic valve? J Thorac Cardiovasc Surg 2016; 151: 1239-1245, 1248.e1-2.

22. Gillinov AM, Faber CN, Sabik JF, Pettersson G, Griffin BP, Gordon SM, Hayek E, Di Paola LM, Cosgrove 3rd DM, Blackstone EH. Endocarditis after mitral valve repair. Ann Thorac Surg 2002; 73: 1813-1816.

23. Gillinov AM, Cosgrove DM, Blackstone EH, Diaz R, Arnold JH, Lytle BW, Smedira NG, Sabik JF, McCarthy PM, Loop FD. Durability of mitral valve repair for degenerative disease. J Thorac Cardiovasc Surg 1998; 116: 734-743.

24. Alvarez JM, Deal CW, Loveridge K, Brennan P, Eisenberg R, Ward M, Bhattacharya K, Atkinson SJ, Choong C. Repairing the degenerative mitral valve: ten to fifteen years follow-up. J Thorac Cardiovasc Surg 1996; 112: 238-247.
25. Weber C, Petrov G, Luehr M, Aubin H, Tugtekin SM, Borger MA, Akhyari $P$, Wahlers T, Hagl C, Matschke K, Misfeld M. Surgical results for prosthetic versus native valve endocarditis: a multicenter analysis. J Thorac Cardiovasc Surg 2019 doi:10.1016/j.jtcvs.2019.09.186.

26. Wang A, Athan E, Pappas PA, Fowler Jr VG, Olaison L, Paré C, Almirante B, Mu ńoz P, Rizzi M, Naber C, Logar M, Tattevin P, Iarussi DL, Selton-Suty C, Braun Jones S, Casabé J, Morris A, Corey GR, Cabell CH. Contemporary clonical profile and outcome of prosthetic valve endocarditis JAMA 2007; 297: 1354-1364.

27. Gnann JW, Dismukes WE. Prosthetic valve endocarditis: an overview. Herz 1983; 8: 320-331. 